\title{
Epidemic Alert System: A Web-based Grassroots Model
}

\author{
Etinosa Noma Osaghae ${ }^{1}$, Kennedy Okokpujie ${ }^{2}$, Charles Ndujiuba $^{3}$, Olatunji Okesola ${ }^{4}$, \\ Imhade P. Okokpujie ${ }^{5}$ \\ ${ }^{1,2,3}$ Department of Electrical and Information Engineering, Covenant University, Nigeria \\ ${ }^{4}$ Department of Computer and Information Science, Covenant University, Nigeria \\ ${ }^{5}$ Department of Mechanical Engineering, Covenant University, Nigeria
}

\begin{tabular}{l}
\hline Article Info \\
\hline Article history: \\
Received May 3, 2018 \\
Revised Aug 20, 2018 \\
Accepted Aug 27, 2018 \\
\hline Keyword: \\
Alert \\
Disease \\
Epidemic \\
Health-care \\
Infectious \\
Model \\
Surveillance \\
Traditional \\
Web-based \\
\hline
\end{tabular}

\begin{abstract}
Most web-based disease surveillance systems that give epidemic alerts are based on very large and unstructured data from various news sources, social media and online queries that are parsed by complex algorithms. This has the tendency to generate results that are so diverse and non-specific. When considered along with the fact that there are no existing standards for mining and analyzing data from the internet, the results or decisions reached based on internet sources have been classified as low-quality. This paper proposes a web-based grassroots epidemic alert system that is based on data collected specifically from primary health centers, hospitals and registered laboratories. It takes a more traditional approach to indicator-based disease surveillance as a step towards standardizing web-based disease surveillance. It makes use of a threshold value that is based on the third quartile $\left(75^{\text {th }}\right.$ percentile) to determine the need to trigger the alarm for the onset of an epidemic. It also includes, for deeper analysis, demographic information.
\end{abstract}

Copyright $(2018$ Institute of Advanced Engineering and Science. All rights reserved.

\section{Corresponding Author:}

Kennedy Okokpujie,

Departement of Electrical and Information Engineering,

Covenant University,

Ota, Ogun State, Nigeria.

Email: kennedy.okokpujie@covenantuniversity.edu.ng

\section{INTRODUCTION}

In the last quarter of the year 2017, a rare disease known as Monkey Pox, broke out in Nigeria, a nation in the western part of Africa. The information about the disease outbreak got to the Nigeria Centre for Disease Control (NCDC) through the Niger Delta University Teaching Hospital (NDUTH), Okolobiri, Bayelsa State. By the end of the year, a total of forty three (43) cases spread across eight states in Nigeria have been confirmed. New cases of the Monkey Pox disease stopped being reported in Nigeria by the start of the year 2018. This was quite laudable as Nigeria uses traditional surveillance methods to watch out for disease outbreaks [1]. This case study reinforces the need to detect the outbreak of infectious diseases at the earliest stage, especially at this time when the world has become a "global village". Thus, nations invest heavily on disease surveillance systems. The reason is not far-fetched, the outbreak of an infectious disease, if not contained at its earliest stage, could lead to catastrophic local, national and world-wide consequences. Economies can be brought to their knees by epidemics that could not be contained because it was not detected early.

The internet has become a powerful tool for detecting epidemics at its earliest stage, it has made it possible to collate and deliver information on the progression of disease outbreaks, epidemics and in some cases, pandemics within days or even hours. The power of the internet is now being explored on a worldwide scale for disease surveillance. A lot of attention has been shifting lately to the possibilities embedded in the internet for web-based disease surveillance [2]. Today, a lot of web-based systems serve the world in various 
languages and utilize data from news sources and social media to detect epidemics at their earliest stage. These web-based disease surveillance systems are sometimes restricted, semi-restricted or freely accessible to the public.

Event-based surveillance systems usually utilize data from online sources. The data acquired could be moderated or aggregated automatically. Syndromic-based surveillance and indicator-based surveillance system make use of health data from healthcare providers, diagnostic laboratories and surveillance specialists in governmental organizations. There also exists a whole arsenal of web-based disease surveillance systems that give early alerts about the outbreak of diseases based on queries made by internet users. The main goal of all these web-based systems remains the early detection of an epidemic outbreak.

The United States can boast of Program for Monitoring Emerging Diseases (ProMED-mail) and Epi-SPIDER for web-based disease surveillance and bio-security intelligence. Other well-known disease surveillance systems like Influenzanet (Europe), The Global, Public Health Intelligence Network - GPHIN (Canada), The Global Outbreak Alert and Response Network (GOARN) and Google Flu Trends are webbased. These web-based epidemic alert systems all make use of data mined from the internet and complex algorithms to analyze data for useful information on disease outbreaks. But most of these systems extract information from a large pool of data on a very large number of infections and thus have difficulty presenting critical information concisely and without ambiguities. The reason for this is simply the fact that till date, no sound methodology has been developed for measuring the relationship between data mined on health related issues from the internet and actual public health related issues like epidemics and pandemics.

In this paper, a shift to the use of a more traditional approach that is web-based is proposed. It would make use of clinical data from primary health centers, diagnostic laboratories and hospitals. The data collected would be classified using the syndromic codes contained in the tenth revision of The International Classification of Diseases (ICD-10). A weekly percentile check forms the basis for determining if a disease has reached epidemic levels. Algorithms working at the background analyses information got from a network of primary health centers, hospitals and laboratories to generate graphically illustrated results about fifty (50) diseases including those on the World Health Organization (WHO) watch list. A threshold based on the third quartile (75th Percentile) for each week was to determine when to trigger the epidemic alert. Diseases on the watch list, when detected, trigger a special alarm. Information like demographics and location were also included for more detailed analysis.

\section{LITERATURE REVIEW}

\subsection{The big argument}

The big argument about the true difference between the words, Epidemic and Pandemic was addressed by David M. Morens et al [3]. In a bid to describe pandemics, the researchers elucidated on eight key factors that tend to characterize a widespread infection as a pandemic. In the expository, the researchers surmised that a disease can be termed pandemic if:

a. It covers a very large geographic area. Trans regional (greater than or equal to two adjacent regions of the world); inter regional (greater than or equal to two non-adjacent regions) and global.

b. It can be traced from place to place as it progresses.

c. It spreads explosively and has a high attack rate.

d. The population has a minimal immunity to it.

e. If it is novel (like HIV/AIDS), through a new strain of the same pathogen.

f. If it is very contagious without specific regards to the means by which it is spread.

g. If it is very severe.

In all, the authors concluded that having the term Pandemic, defined as a large epidemic makes sense and avoids the pitfalls of inconsistency. In addition, the researchers suggested that the term pandemic be used for only infectious diseases.

\subsection{Web-based disease surveillance and epidemic alert system: state-of-the-art}

Erini reviewed some of the latest technologies and tools used to carry out regional and global infectious disease surveillance [4]. A review on epidemic modeling was also done. The need to be able to quickly and efficiently classify previously unknown strains of pathogens that are responsible for emerging infectious diseases was stressed. Disease surveillance with the latest and most effective tools was also encouraged to ensure that novel and re-emerging infectious diseases do not attain epidemic/pandemic levels. The author emphasized the need for large-scale infectious disease surveillance networks, especially in the world of today that is fast becoming smaller due to "never-seen-before" bridges in communication and transportation gaps. The author highlighted event-based surveillance, web-based real-time surveillance, early 
warning and alert response networks, infectious diseases modeling, social media and new technologies in pathogen discovery as the key drivers in the new age of disease surveillance.

Collier, of the National Institute of Informatics, Tokyo, Japan did a survey on the importance of Epidemic Intelligence (EI). The focus of the researcher's work was a survey on the use of artificial intelligence, social network, data mining tools and natural language processors to monitor the progress of disease outbreaks from predominantly unstructured data. He surmised that at the core of Epidemic Intelligence using unstructured data was the technology called Text Mining [5].

In their work, Jennifer L. Gardy et al shed light on the need to develop a disease surveillance system that is global in scope, works on the go and is genomics-informed especially iafter the Ebola and Zika epidemics. The researchers proposed a One Health System that is based on genomics diagnostics and epidemiology integration into existing disease surveillance systems [6]. The researchers envisioned a system that integrates human, animal and environmental health to proffer disease surveillance solutions to regions of the world with inadequate to non-existent laboratory facilities [7]. The researchers paid particular attention to how several epidemics like the Ebola and Zika progressed uninhibited for months and unnoticed by even the most advanced disease surveillance systems until they were discovered much later when they have grown to epic proportions. Novel pathogen identification and the detection of certain old pathogens in new regions were identified as the major gaps in all existing disease surveillance systems. Major impediments to the One Health Scheme proposed by the researchers were identified as government policies, conflicts between medical practitioners and researchers from lower income, middle income and better resourced nations. The future of disease surveillance as highlighted by the researchers is the genomics-informed [8] one where all the factors affecting health are considered on a global scale with complete and uninhibited transparency.

S.J. Yan et al explored the accuracy and timeliness of data mined from unstructured sources on the internet for Epidemic Intelligence (EI). The researchers surveyed a lot of publications on the subject of Text Mining for Epidemic Intelligence and came up with the conclusion that serious attention should be paid to the timeliness and accuracy of information about disease outbreaks got from mining ubiquitous, free and unstructured data from the internet [9].

Simon Pollet et al focused on the use of "Big Data" to get Epidemic Intelligence (EI) on vectorborne diseases (VBD) in middle and low income countries [10]. The research was a review on the performance of various internet-based tools and techniques that have been employed to mine data on vectorborne disease. The researchers carried out an in-depth survey and came to the conclusion that more reviews need to be done to ascertain the true impact of using "Digital Epidemiology" in tandem with more conventional or traditional means of disease surveillance. The research also called for more surveys on the reaction of end users to the metrics used to classify or gauge the outbreak of a disease. The researchers also emphasized that "Digital Epidemiology" was not made to replace but rather complement traditional methods of vector-borne disease surveillance.

Eun Kyong Shin et al looked closely at the progress of online clinical trials in the United States of America. The research focused on the popularity and impact of online clinical trials and health studies from the first time it appeared online and its perceived future. The research work also exhaustively detailed the potential and obvious use of the internet for health studies.

Natalie S. and Collins A. in the article, Web-based Surveillance of Illness in Childcare Centers, made a proposal for active bio-surveillance in childcare centers [11]. The authors were of the opinion that monitoring childcare centers for disease outbreak was more effective than the traditional method of monitoring schools only. The article pointed out summer breaks as one of the main or core reasons why monitoring schools only for disease outbreaks was not effective enough. The authors also proposed that the bio-surveillance of childcare centers be web-based and should submit reports on a weekly basis to the central public health department. Some of the key metrics or data that was monitored by the proposed child care biosurveillance program were children categories (toddlers, infants and pre-schoolers) and the illness reported. The statistical report was expressed in terms of percentages and actual whole numbers for each major category. The authors claimed that the system, implemented in a Michigan County (United States of America), was able to detect the outbreak of Gastroenteritis and Hand-Foot-Mouth disease when the more conventional school based disease monitoring system was not available, especially during winter and summer seasons.

The Global Public Health Intelligence Network (GPHIN) was credited with sending the first alert on the Acute Respiratory Illness Outbreak, code-named, MERS-CoV (Middle East Respiratory Syndrome Coronavirus) [12]. It is a web-based program that uses specialized algorithms to harness the power of Big Data to mine for clues that signal the onset of an epidemic. The web-based program, in conjunction with a multilingual and multidisciplinary team, culled and analyzed information from over thirty thousand sources in nine languages for potential clues to the onset of an epidemic anywhere in the world. The authors made it known that the system is being adopted by many nations for national disease surveillance. The authors 
emphasized how future GPHIN projects plan to utilize more of the power of Big Data especially from social media outlets using sophisticated algorithms to mine for epidemic clues.

The use of drivers of emerging infectious diseases [13], [14] was suggested by Sarah H. Olson et al to develop the framework for digital detection of Infectious Disease (ID) events. The researchers were of the opinion that close monitoring of infectious disease drivers could provide a viable means for the early detection of potential infectious disease epidemics especially in the case of emerging infectious diseases. The researchers identified some of these drivers as climate and meteorological data. The researchers also presented a sample framework for the use of Infectious Disease (ID) drivers in digital disease surveillance programs. An extensive review of previous infectious driver models was also done and the gaps were identified.

Nsoesie et al carried out an extensive review of the most recent digital technologies that have been employed for infectious disease surveillance at mass gathering events. Interestingly, among the digital technologies was the internet or web-based approach to disease surveillance at mass gathering event [15]. Notable among the web-based digital disease surveillance for mass gathering events was the Healthcare Electronic Surveillance Network (HESN) implemented by the Kingdom of Saudi Arabia to closely monitor respiratory, gastrointestinal, cardiovascular, skin and ear/nose diagnoses. The system was said to have been very effective during the 2013 Hajj season. The HESN captures diagnostic data from healthcare practitioners, clinic and hospital staff, paramedics and other health related outfits for semi-automatic analysis and prompt decision taking. In the 2002 Salt Lake City winter games, a web-based and fully automated infectious disease surveillance system was used to analyze health data from several sources and most prominent was the triggering of an alert if any disease outbreak is suspected. The system actually gave two alerts for respiratory infections that were promptly put addressed by health officials. The impact of web-based epidemic alert systems during many other mass gathering events like the world cup and religious gatherings were elucidated. Small gatherings were not left out. A good example given was the use of a combo of the Global Public Health Intelligence Network (GPHIN) and Medical System (Medisys), all web-based disease surveillance systems, for the infectious disease surveillance during the 2012 European football championship.

Some researchers [16] carried out a systematic review to determine the extent and depth to which Online Social Networks (OSNs) have been used for disease surveillance. The study submitted that lots of models, framework and systems for disease surveillance using online social networks have been developed and in many cases, implemented. The researchers acknowledged the fact that online social media provides a viable means of tracking pandemics because of its vast and varied, though unstructured nature. The large population of people from various places all-over the world and the exchange of information that goes on unabated via social media platforms have been mined and analyzed by an array of complex algorithms and computational linguistics to track pandemics. The criteria used for each OSN pandemic tracking system were numerous and made it clear that the use of online social networks to track the onset or progress of a pandemic may never replace traditional and more conventional methods of disease surveillance.

The need for web-based disease surveillance is also being explored and implemented by the armed forces as seen in the joint bio-surveillance portal championed by the Republic of Korea and the United States of America [17].

The use of purely traditional means of disease surveillance and the emergence of the WHO as the international instrument for the expediting of intervention programs in the event of unusual and especially tough epidemics and pandemics has led to the disappearance of a number of infectious diseases around the world [18]. But emphasis today keeps shifting towards real-time disease surveillance [19]. The report submitted that the state-of-the-art for real-time disease surveillance depends heavily on social media.

Jihye choi et al also reviewed various web-based infectious disease surveillance systems that have been used. The study focused on the current state-of-the -art, benefits and challenges associated with webbased disease surveillance systems that have been implemented in various ways to support the more conventional or traditional surveillance methods [20]. The authors looked closely at the strengths and weaknesses of eleven web-based surveillance systems and gave comments on how the weakness of some of the web-based surveillance methods already in use, can be improved. The researchers did submit that webbased disease surveillance methods were adaptable, low-cost, and intuitive and can be operated in real-time. The researchers identified privacy issues, prediction and an interpretation inaccuracy as some of the potential challenges of internet-based epidemic alert systems. The authors also noted the absence of a functional webbased epidemic monitoring systems in some nations with advanced information and communication technology presence. The authors also classified standard disease surveillance systems and a lot of them were web-based. This is shown in Figure 1. 


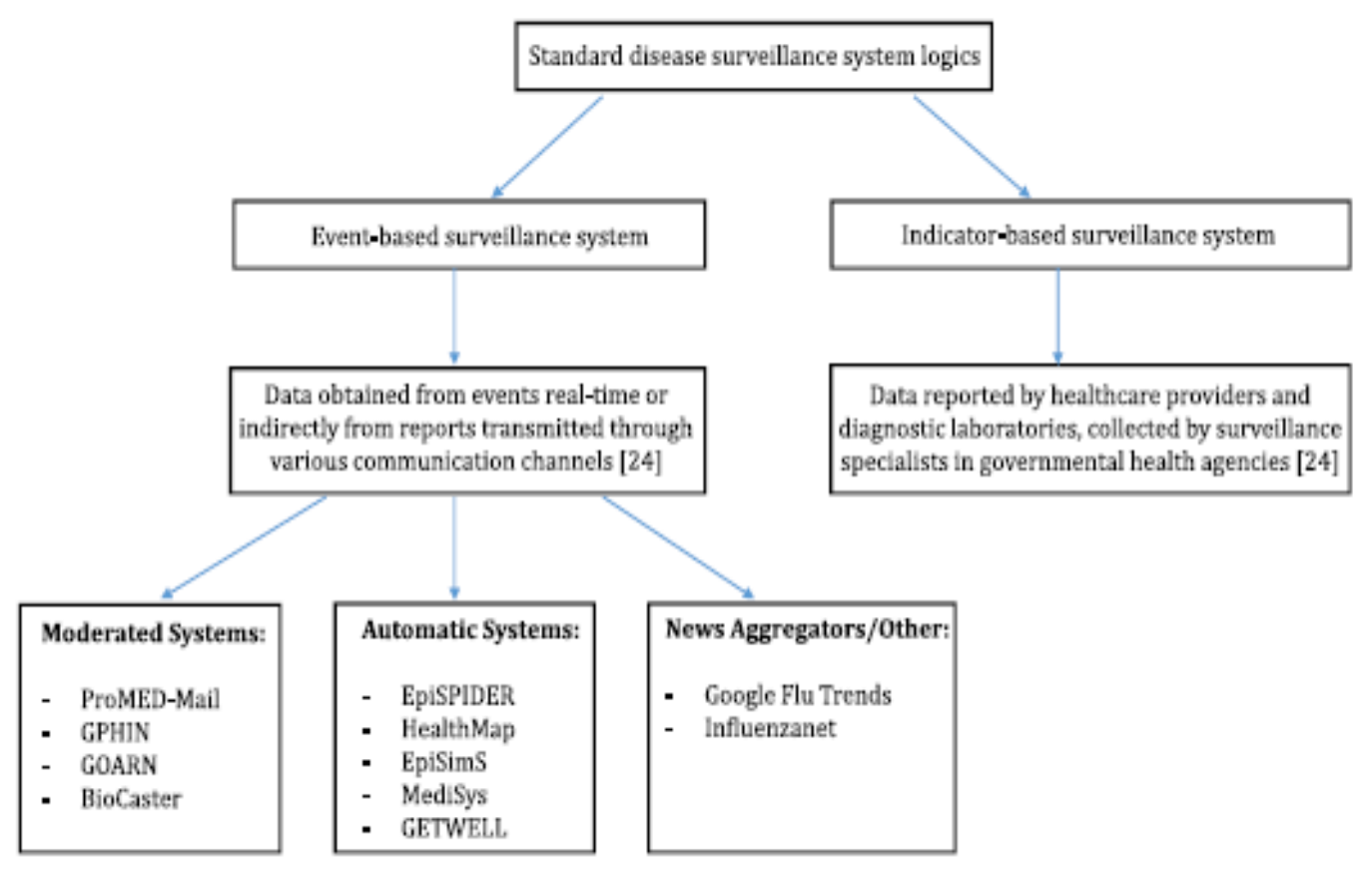

Figure 1. Classification of standard disease surveillance systems [20]

A research work carried out during a project backed by the European Commission, acknowledged the high outlay of capital on electronic disease surveillance systems to help in detecting the outbreak of emerging and re-emerging infections on time. The report submitted that it remains unclear if existing and sophisticated real-time electronic surveillance systems can effectively detect the outbreak of an epidemic early.

The Sustainable Surveillance Workgroup made some suggestions on how to build a sustainable disease surveillance system [22] that is equipped to provide information about infection outbreak continuously. The report supported the need to know that continuous and unabated disease surveillance is a must for the benefit of public health. The report also stressed the need to improve on the monetary allotment for surveillance purpose, have an active surveillance workforce and delve into deep rigorous disease surveillance research that would lead to a better understanding of public health and help with the creation of policies and decision making.

The lessons learned from the various implementations of web-based disease surveillance systems can be seen in the article written by MO Lwin et al of how Mo-Buzz [23], a mobile pandemic surveillance system for Dengue was implemented in Colombo, Sri Lanka. The mobile application was developed to take advantage of Sri Lanka's large mobile device using population. The study submitted that the traditional Dengue reporting structure in Sri Lanka was excruciatingly slow because it was still paper based. The introduction of Mo-Buzz in two phases, one for the general public and another for Sri Lanka's health institutions, led to a boost in the country's ability to detect, keep track and inform the public about Dengue disease outbreaks. The researchers noted that though Mo-Buzz's initial uptake was quite low, it picked up and went as high as $76 \%$. This study confirms the fact that mobile and social media outlets which are all web-based are the future for global disease surveillance [24].

\subsection{Traditional and syndromic surveillance of infectious diseases and pathogens}

Cedric Abat et al noted that many disease surveillance systems are in use all around the world [25]. The reasearchers made a summary of some disease surveillance methods in use all around the world. The researchers looked at syndromic surveillance from the microbiology perspective. The researchers submitted that disease surveillance data can be gathered from the Human Environment with focus on Environmental data (water pollution, weather, and air pollution) and Animal Health data (information about the health of domestic and wild animals). Surveillance data can also be got from human behaviour, which consists of Internet use (web queries, press dispatches, social media, press articles), Telephone (hotlines), Drug sales and Absenteeism. Health Care also provide viable disease surveillance data via Sentinel surveillance (sentinel physicians who agree to notify the public health authorities at regular intervals of patients presenting certain 
specific symptoms of infectious diseases on the watch list), Chief complaints, Medical records, Hospital discharge data, Microbiology orders, Disease reports and Demographics.

The researchers listed some surveillance strategies such as Disease-specific surveillance, Eventbased surveillance and Syndromic surveillance [26].

\subsection{Infodemiology metrics}

Infodemiology helps deternine the best way to tackle the issue of public health. It is possible to collect data for this information in real-time. Internet queries have been used to predict the outbreak of an epidemic. Twitter microblogs, the news and the way people use the internet for health services have been monitored. The information gleaned from all these numerous sources are analysed and useful information that can be used to inform about health policies are inferred [27]. A lot of metrics have been used to gauge the impact of information got from the internet.

It has been said that there is a need to standardize infodemiology and inforsurveillance metrics. Infodemiology is primarily and electronic (got using some kind of algorithm). According to the authors, infodemiology's most basic metrics could be supply related (internet users postings) or demand related (internet users buying habits) [28]. On the supply side, the most basic metrics were information prevalence and information occurrence ratios. On the demand side, the most basic metrics were the number of searches of a specific topic and number of clicks on a website about a specific topic. An active method involving online surveys of consumers of health products also provides for a good infodemiology metric.

\subsection{Models for web-based surveillance and epidemic alert systems}

The ubiquitous and pervasive powers of the internet and social media have forced many states to revise their disease surveillance policies. It is almost a must for states to carry out active disease surveillance and inform the World Health Organization (WHO) of any epidemic outbreak. Individuals and nongovernmental organizations have continued unabatedly to use the power of social media, the internet and complex algorithms to report cases of epidemic outbreaks to WHO and in many instances, before it is known and accepted officially [29]. The model is shown in Figure 2.

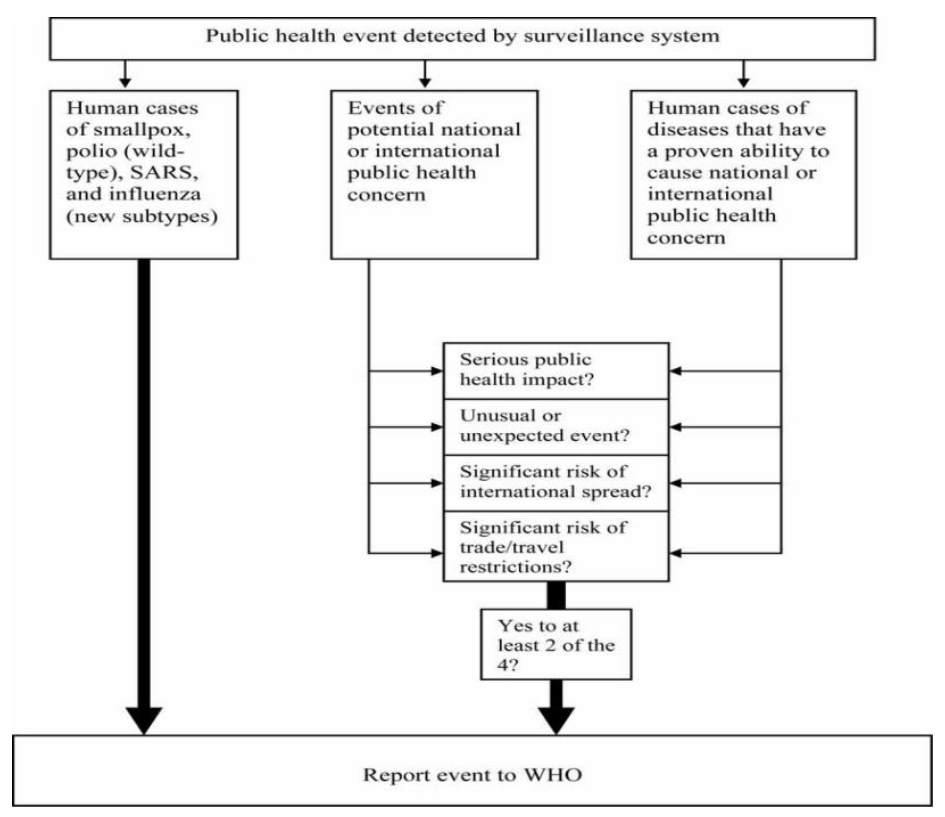

Figure 2. Decision-making instrument for International Health Regulation - IHR (2005), adapted from Annex 2 [29]

WHO has an integrated global alert and response system for epidemics and pandemics. The system is based on already existing and effective national health systems and an international coordinated response system. Presently, WHO get alerts about epidemics and pandemics through the health care system of its member states? The model uses phases of this nature for zoonotic diseases; 
Phase 1-3: The phase for preparing, gathering up-to-date information and planning for emergency response.

Phase 4-6: Actual emergency response and mitigating efforts.

In a more detailed format, the various phases have these components:

Phase 1: No human infections. Only animals are affected.

Phase 2: Humans have been infected but at very low to non-existent levels.

Phase 3: A tangible number of humans infections have been recorded but no human-human transmissions yet.

Phase 4: Verified and recorded human-human infection with attendant "community-level outbreaks" or full epidemic.

Phase 5: Verified and recorded human-human infection with attendant "community-level outbreaks" in at least two countries within a defined WHO region. Pandemic is very imminent.

Phase 6: Verified and recorded human-human infection with attendant "community level outbreaks" in at least two countries within a defined WHO region and at least one country in a different WHO region. A pandemic is underway.

Presently WHO has made it necessary for all national governments to report cases of any disease on a watch list that keeps growing with new additions.

A Bayesian Hierarchical Poisson Model with a hidden Markov model was proposed by D. Conesa et al for the early detection of influenza epidemic outbreak [30]. The model relied greatly on an intensity parameter that was set by the incidence frequency. The incidence rate was considered as a normal distribution in which its parameters, mean and variance, were modeled to reflect the phase of the system, be it epidemic or non-epidemic. The transition took into cognizance previous weekly epidemic states. The authors gave samples of how to implement the statistical model and used Bayesian Inference to define the state of an influenza epidemic at any moment. The researchers gave the transition probabilities as:

$$
P\left(Z_{i+1, j}=L / Z_{i, j=k}\right)=P_{k, l}, K, L \in\{0,1\}
$$

Where;

$Z_{i, j} \rightarrow$ An observed random variable that indicates the phase of the modeled system as either epidemic (1) or non-epidemic (0)

$P_{k, l} \rightarrow$ Suitable probabilities

$i \rightarrow$ Day (during the week)

$j \rightarrow$ Season

The Moving Epidemic Method (MEM) was used to model the incidence rate of influenza-like illness (ILI) and Acute Respiratory Illness (ARI) for some European countries by [31]. The values obtained were used to compute the various intensity levels adopted by the research, namely, Baseline, Low, Medium, High and very High. The researchers used these benchmarks to compare the epidemic level of ILI in various European nations for different time periods from 1996/1997 - 2013/2014 seasons. The authors arrived at the conclusion that these comparisons are important for firm understanding of seasonal epidemic patterns and thus, should be incorporated into automated disease surveillance systems at national and international levels.

In the article, Zika Virus: A New Pandemic Threat [32], allusion was made to a special software application, Zika Tracker, that was used to aid voluntary reporting of confirmed Zika virus infection cases to help the Americas contain the spread of the virus which was suspected to be the main cause of an alarming rise in Microcephaly cases in the Americas. This is one of the very basic examples of a disease alert and monitoring system that exploits disease surveillance at the grassroots.

Ruth A. Ashton et al, gave an insightful expository into the usefulness of school-based disease surveillance with malaria as a case study. [33]. The research focused on a pilot programme that was carried out in Ethiopia to monitor malaria epidemics and focused particularly on school absenteeism and febrile illness. The researchers submitted that a lot of challenges hampered the study. The focus on a school-based system brought a serious challenge of population representation as almost $46 \%$ of Ethiopian school aged children are not enrolled in school. The researchers suggested that another pilot project be carried out again when there is a substantial increase in reported cases of malaria than what is conventionally known. In all, the researchers noted that the sensitivity of the school-based syndromic surveillance to detect epidemics could not be fully ascertained. The Model used is shown in Figure 3.

Four critical areas that pose serious problems to disease surveillance on a global scale were outlined by [34] as scientific methods, international policies, technical resources, financial resources and human resources. The researchers gave a notional scheme for a global disease surveillance and response process. 
Some researchers [35] wrote on how epiDMS: Data Management and Analytics for Decision Making from Epidemic Spread Simulation Ensembles, have helped to plug some critical holes that has to do with scalability, multiple interdependency parameters and complex dynamic processes during an ongoing epidemic. The researchers claimed that the data management and analytics tools offered by epiDMS help with the decision-making process in the event of an epidemic with significant health and economic benefits. Figure 4 depicts the epiDMS model.

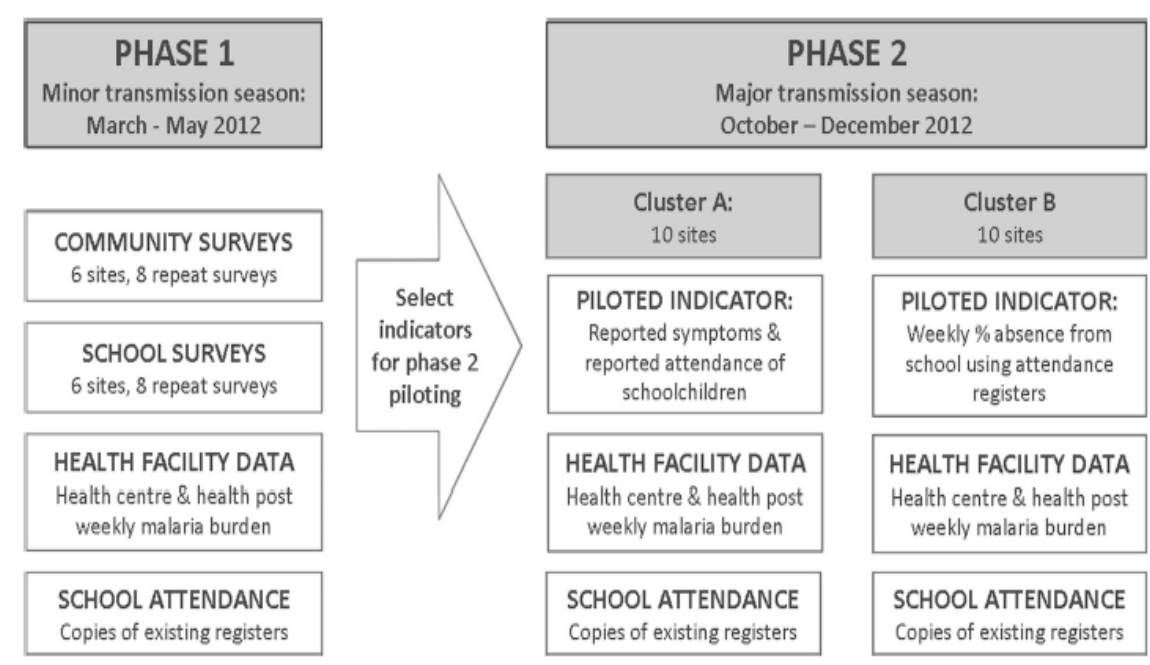

Figure 3. Model for school-based malaria epidemic surveillance system [33]

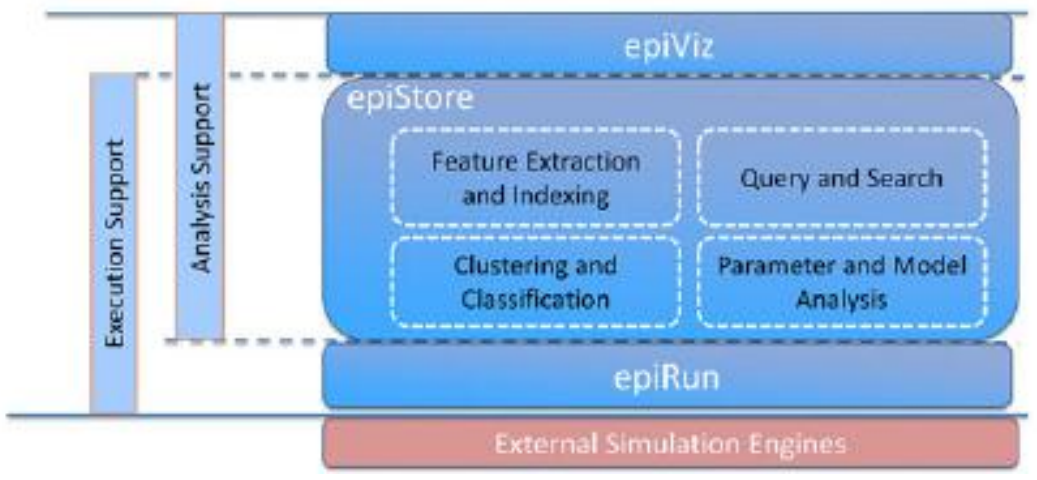

Figure 4. Overview of the epiDMS system [35]

A group of researchers developed an internet-based epidemic alert system for periodontal disease in Nigeria. The web-based model proposed by the researchers was based on real-time statistical data for periodontal disease diagnosis across Nigeria. HTML, PHP and CSS were used to develop the user-friendly interface of the system and MySQL [36] was used to create the database of the system. The researchers claimed that the proposed system will help with the surveying and tracking of periodontal disease in Nigeria [37].

Some researchers[38] used colour code based on the alert phases already defined by WHO to determine and raise an alarm for the outbreak of the AH1N1 Influenza in America. The authors used the Basic Reproduction number $R_{o}$ to know when there is a need to trigger an epidemic alert. The authors utilized accumulated data from sixteen (16) out of the thirty five (35) member states of the Americas to get the Basic Representation number. A Basic Representation number greater than one $(>1)$ was the trigger for the outbreak of an epidemic. 


\section{EPIDEMIC ALERT THRESHOLD ALGORITHMS}

\subsection{The use of change point analysis}

A change point is the point where a structure change occurs in the collected data [39]-[ 40]. The series can be represented as:

$$
\left\{x_{1}, x_{2}, \ldots, x_{n}\right\}
$$

And the index of time, represented as:

$$
T \in\{1,2, \ldots, n\}
$$

The epidemic or endemic component of the process is a piecewise constant. The pre-epidemic period (endemic state), epidemic period (epidemic state) and the post-epidemic (endemic state) would be determined. A changes are first detected, counted and estimate. If $\left\{x_{1}, x_{2}, \ldots, x_{n}\right\}$ is the time series of independent variables and $\theta_{i}$, where $i=1, \ldots, n$ represent the corresponding structure parameters then, a decision has to be made between:

$$
H_{o}: \theta_{1}=\cdots=\theta_{k} \cdots=\theta_{\tau}=\cdots=\theta_{n} \text { No change point }
$$

And

$$
H_{1}: \theta_{1}=\cdots=\theta_{k} \ldots=\alpha \neq \theta_{k+1} \ldots=\theta_{\tau}=\beta=\theta_{\tau+1}=\cdots=\theta_{n}=\gamma \text { Change points }
$$

Note:
a. $1<k<\tau<n$
b. $\alpha, \beta$ and $\gamma$ represents the start and end dates of the outbreak respectively
c. The rejection of $H_{o}$ confirms a change point.

If $H_{o}$ is rejected, the number of changes in state and their actual position has to be estimated. Thus:

If $H_{1}$ is true, what is $k$ and $\tau$ from the sample, $\left\{x_{1}, x_{2}, \ldots, x_{n}\right\}$. This change point problem was solved using the non-parametric kernel model. Based on simulated data, the non-parametric kernel model was used to detect the start of an outbreak and the end of an outbreak.

\subsection{The kernel model}

If $\left\{x_{1}, x_{2}, \ldots ., x_{n}\right\}$ is a true series of independent random variables, the Kernel function is defined as:

$$
Y_{i}=K\left(x_{i}\right) \forall i \in\{1,2, \ldots, n\}
$$

A Kernel Fisher discriminant ratio (KFDR) is used to measure the heterogeneity between successive segments, $S_{1}, S_{2}, S_{3}$.

$S_{1}=\left\{x_{1}, x_{2}, \ldots \ldots, x_{i}\right\}$ with $i$ observations, pre-epidemic.

$S_{2}=\left\{x_{\tau^{1+1}}, x_{\tau^{1+2}}, \ldots, x_{j}\right\}$ with $(j-i)$ observations; epidemic.

$S_{3}=\left\{x_{\tau^{2+1}}, x_{\tau^{2+2}}, \ldots, x_{n}\right\}$ with $(n-j)$ observations; post-epidemic.

A simple linear kernel function:

$k(x, y)=x y$ is used to determine the value of " $k$ "

To find the KFDR between $S_{1}$ and $S_{2}$ :

$$
\operatorname{KFDR}\left(S_{1}, S_{2}\right)=\frac{\operatorname{mean}\left(S_{i}\right)-\operatorname{mean}\left(S_{2}\right)}{\frac{(j-1)}{j} \operatorname{var}\left(S_{1}\right)-\frac{i}{j} \operatorname{var}\left(S_{2}\right)}
$$

$i$ and $j$ are chosen to maximize the heterogeneity between the three segments by calculating:

$$
\begin{aligned}
& V(i, j)=\frac{i(j-1)}{j} \operatorname{KFDR}\left(S_{1}, S_{2}\right)+\frac{(j-i)(n-j)}{n-i} \operatorname{KFDR}\left(S_{2}, S_{3}\right) \\
& \left(\widehat{\tau_{1}, \tau_{2}}\right)=\operatorname{argmax}\left(\tau_{1}, \tau_{2}\right) \in\{1, \ldots, n\} \alpha\{1, \ldots, n\}, \tau_{1}<\tau_{2}\left(\operatorname{KFDR}\left(\tau_{1}, \tau_{2}\right)\right)
\end{aligned}
$$




\section{RESEARCH METHOD}

The web-based grassroots model assumes a medical history and uses the third quartile value for each disease under consideration to set the threshold that would determine when a disease has reached epidemic levels. The proposed system uses the weekly percentile.

The World Health Organization suggested the use of the third quartile $\left(75^{\text {th }}\right.$ Percentile) as a threshold for triggering the onset of an epidemic [41].

$$
P_{i}=L+\left[\frac{n_{p}-c_{f}}{f_{i}}\right] . w
$$

$P_{i} \rightarrow$ The $i^{\text {th }}$ percentile

$L \rightarrow$ Limit below the the desired percentile point's interval

$n \rightarrow$ Total available scores

$p \rightarrow$ The score point in terms of desired percentile

$C_{f} \rightarrow$ Summation of frequency scores below the percentile point's interval

$f_{i} \rightarrow$ The $i^{\text {th }}$ percentile poin's frequency scores

$w \rightarrow$ Class interval width

A baseline or threshold is set, beyond which a disease has reached epidemic levels. The "Low" alarm is triggered when the seventy fifth percentile value (third quartile) for a given disease is higher than the baseline at any given week. The "Moderate" alarm is triggered when the third quartile value of a given disease is higher than the baseline for two consecutive weeks. The "High" alarm is triggered when the third quartile value of a given disease is higher than the baseline for three consecutive weeks. The "Severe" alarm is triggered when the third quartile value of a given disease is higher than the threshold for four consecutive weeks.

On the user side, data collected using the proposed web-based grassroots model includes:

1. Medical: Centre Code, Age, Sex, Symptoms, Diagnosis (50 ICD codes were used in this demonstration).

2. Microbiology Orders: Laboratory Centre code and Pathogen.

3. Notifiable Disease Report: Express Notification by Sentinel Surveillance.

On the administrator side, data monitored include:

1. Dashboard: Special Alerts and Express Notification by Sentinel Surveillance.

2. Percentile graphs: Daily and Weekly Percentile Graphs.

The International Classification of Diseases (ICD-10) codes and their respective threshold based on previously known (assumed in this case) weekly third quartile values for the sample diseases monitored by the proposed web-based grassroots model are shown in Table 1.

Table 1. ICD Codes and their Third Quartile Baseline

\begin{tabular}{|c|c|c|c|}
\hline $\mathrm{S} / \mathrm{N}$ & Disease & ICD Code & $\begin{array}{c}\text { Third Quartile } \\
\text { Baseline }\end{array}$ \\
\hline 1 & Cholera* & A00 & 5 \\
\hline 2 & Plague* & A 20 & 0 \\
\hline 3 & Yellow Fever* & A95 & 0 \\
\hline 4 & Small Pox* & B03 & 0 \\
\hline 5 & Relapsing Fever* & A68 & 0 \\
\hline 6 & Typhus* & A75 & 15 \\
\hline 7 & Polio* & A 80 & 0 \\
\hline 8 & $\begin{array}{c}\text { Severe Acute } \\
\text { Respiratory } \\
\text { Syndrome } \\
\text { (SARS)* }\end{array}$ & $\mathrm{J} 60$ & 30 \\
\hline 9 & $\begin{array}{l}\text { Ebola virus } \\
\text { disease* }\end{array}$ & A98-4 & 0 \\
\hline 10 & Influenza* & $\mathrm{J} 10$ & 0 \\
\hline 11 & $\begin{array}{l}\text { Lassa Fever* } \\
\text { Marburg }\end{array}$ & A96-2 & 0 \\
\hline 12 & $\begin{array}{l}\text { Hemorrhage } \\
\text { Fever* }\end{array}$ & A98-3 & 0 \\
\hline 13 & Rift Valley Fever* & A92-4 & 0 \\
\hline 14 & $\begin{array}{l}\text { Tularemia* } \\
\text { Dengue }\end{array}$ & $\mathrm{A} 21$ & 0 \\
\hline 15 & $\begin{array}{c}\text { Hemorrhagic } \\
\text { Fever* }\end{array}$ & A91 & 0 \\
\hline
\end{tabular}




\begin{tabular}{|c|c|c|c|}
\hline $\mathrm{S} / \mathrm{N}$ & Disease & ICD Code & $\begin{array}{c}\text { Third Quartile } \\
\text { Baseline }\end{array}$ \\
\hline 16 & $\begin{array}{c}\text { Crimean-Congo } \\
\text { Hemorrhagic } \\
\text { Fever* }\end{array}$ & A98-0 & 0 \\
\hline 17 & Anthrax* & $\mathrm{A} 22$ & 0 \\
\hline 18 & Monkeypox & B04 & 12 \\
\hline 19 & Candidiasis & B37 & 10 \\
\hline 20 & HIV/AIDS & B20 & 20 \\
\hline 21 & Diarrhea & A09 & 30 \\
\hline 22 & Tuberculosis & A16 & 50 \\
\hline 23 & Rabies* & A82 & 0 \\
\hline 24 & Botulism & A05-1 & 23 \\
\hline 25 & Campylobacteriosis & A04-5 & 15 \\
\hline 26 & Chickenpox & B01 & 35 \\
\hline 27 & $\begin{array}{l}\text { Creutzfeldt-Jakob } \\
\text { Disease }\end{array}$ & A81-0 & 20 \\
\hline 28 & $\begin{array}{l}\text { Dysentery } \\
\text { Hantavirus }\end{array}$ & A06-0 & 12 \\
\hline 29 & $\begin{array}{l}\text { Pulmonary } \\
\text { Syndrome }\end{array}$ & $\mathrm{I} 26$ & 11 \\
\hline 30 & Helicobacter Pylori & K31-2 & 5 \\
\hline 31 & Hepatitis B & B16 & 12 \\
\hline 32 & Hepatitis C & B17-1 & 12 \\
\hline 33 & Histoplamosis & B39 & 2 \\
\hline 34 & Leptospirosis & A 27 & 35 \\
\hline 35 & Lyme Disease & A69-2 & 13 \\
\hline 36 & Measles & B05 & 15 \\
\hline 37 & Mumps & B26 & 15 \\
\hline 38 & $\begin{array}{c}\text { Typhoid and } \\
\text { Paratyphoid Fevers }\end{array}$ & A01 & 70 \\
\hline 39 & Diptheria & A36 & 48 \\
\hline 40 & Schistosomiasis & B65 & 50 \\
\hline 41 & Tetanus & A33 & 10 \\
\hline 42 & Taxoplasmosis & B58 & 25 \\
\hline 43 & Leprosy & A 30 & 10 \\
\hline 44 & Viral meningitis & A87 & 10 \\
\hline 45 & West Nile Virus & A92-3 & 10 \\
\hline 46 & Dyspepsia & $\mathrm{K} 30$ & 25 \\
\hline 47 & Hepatitis A & B15 & 60 \\
\hline 48 & Whooping Cough & A 37 & 5 \\
\hline 49 & Malaria & B50 & 100 \\
\hline 50 & Scabies & B86 & 35 \\
\hline
\end{tabular}

*The asterisked diseases on a special watch list

NOTE: The International Statistical Classification of Diseases (ICD) - 10 codes used herein does not take into cognizance subsets of the code for disease variations and causative organisms.

For demographic analysis, codes were assigned to hospitals, primary health centres and laboratories that provide inputs to the epidemic alert system. Table 2 shows some sample centre code for hospitals, laboratories and primary health centres that were used to demonstrate how the proposed epidemic alert model works. Table 3 shows a sample of the inputs got from Laboratories. Table 4 shows a sample of the inputs got from medical records in hospitals and primary health centres. Figure 7 shows the algorithm for the proposed web-based grassroots epidemic alert system.

Table 2. Centre Codes

\begin{tabular}{cccc}
\hline S/N & Centre Code & Type & Location \\
\hline 1 & H01865360875 & Hospital & Marque, Kingston \\
2 & P12765098656 & Primary Health Centre & Dale, Lofty Heights \\
3 & P37659339059 & Primary Health Centre & Tomahawk, Prowess \\
4 & L78599539584 & Laboratory & Balinese, Catwalk \\
5 & H24698736483 & Hospital & Cross, Time Hills \\
6 & H54786783995 & Hospital & Action Yard, Trent \\
7 & P84898479948 & Primary Health Centre & Hague, Bella vane \\
8 & H67494672997 & Hospital & Seminary Zone, \\
9 & L75643782674 & Laboratory & Primer \\
10 & P98573652641 & Primary Health Centre & Hebron, Simile \\
\hline
\end{tabular}


Table 3. Microbiology Orders

\begin{tabular}{|c|c|c|}
\hline Centre Code & Pathogen & $\begin{array}{c}\text { Test } \\
\text { counts }\end{array}$ \\
\hline \multirow{3}{*}{ H01865360875 } & Vibro Cholerae Plasmodium & 5 \\
\hline & Spp & 13 \\
\hline & Salmonella Spp & 6 \\
\hline \multirow{3}{*}{ P12765098656 } & Vibro Cholerae Plasmodium & 3 \\
\hline & Spp & 15 \\
\hline & Salmonella Spp & 18 \\
\hline \multirow{3}{*}{ P37659339059 } & Vibro Cholerae Plasmodium & 6 \\
\hline & Spp & 45 \\
\hline & Salmonella Spp & 12 \\
\hline \multirow{3}{*}{ L78599539584 } & Vibro Cholerae & 4 \\
\hline & Plasmodium Spp & 20 \\
\hline & Salmonella Spp & 7 \\
\hline \multirow{3}{*}{ H24698736483 } & Vibro Cholerae & 8 \\
\hline & Plasmodium Spp & 34 \\
\hline & Salmonella Spp & 9 \\
\hline \multirow{3}{*}{ H54786783995 } & Vibro Cholerae & 2 \\
\hline & Plasmodium Spp & 12 \\
\hline & Salmonella Spp & 5 \\
\hline \multirow{3}{*}{ P84898479948 } & Vibro Cholerae Plasmodium & 7 \\
\hline & Spp & 60 \\
\hline & Salmonella Spp & 1 \\
\hline \multirow{3}{*}{ H67494672997 } & Vibro Cholerae Plasmodium & 2 \\
\hline & Spp & 31 \\
\hline & Salmonella Spp & 4 \\
\hline \multirow{3}{*}{ L75643782674 } & Vibro Cholerae & 8 \\
\hline & Plasmodium Spp & 15 \\
\hline & Salmonella Spp & 12 \\
\hline \multirow{3}{*}{ P98573652641 } & Vibro Cholerae & 6 \\
\hline & Plasmodium Spp & 9 \\
\hline & Salmonella Spp & 4 \\
\hline
\end{tabular}

Table 4. Medical Records

\begin{tabular}{|c|c|c|c|}
\hline Centre Code & Age & Sex & $\begin{array}{c}\text { Diagnosis (ICD-Code) } \\
\text { - Counts }\end{array}$ \\
\hline \multirow[t]{6}{*}{ H01865360875 } & $0-1$ (Infant) & Male & $\begin{array}{l}\text { B50-23, A01-4, A00 } \\
-21, \text { B } 05-1, \text { B } 01-2, \\
\text { A09-1, A } 80-3, \text { B } 86 \\
-2,\end{array}$ \\
\hline & & Female & $\begin{array}{l}\mathrm{B} 50-5, \mathrm{~A} 00-0, \mathrm{~B} 16 \\
-7, \mathrm{~B} 37-1 . \mathrm{B} 50-23, \\
\mathrm{~A} 01-3, \mathrm{~A} 00-12, \mathrm{~B} 05 \\
-0, \mathrm{~B} 01-2, \mathrm{~A} 09-0, \\
\mathrm{~A} 80-3, \mathrm{~B} 86-2, \mathrm{~B} 50 \\
-5, \mathrm{~A} 00-0, \mathrm{~B} 16-1, \\
\text { B } 37-0 .\end{array}$ \\
\hline & $1-4$ (toddler) & Male & $\begin{array}{l}\mathrm{B} 50-23, \mathrm{~A} 01-7, \mathrm{~A} 00 \\
-21, \mathrm{~B} 05-1, \mathrm{~B} 01-2, \\
\mathrm{~A} 09-1, \mathrm{~A} 80-3, \mathrm{~B} 86 \\
-2, \mathrm{~B} 50-5, \mathrm{~A} 00-0, \\
\mathrm{~B} 16-7, \mathrm{~B} 37-0 .\end{array}$ \\
\hline & & Female & $\begin{array}{l}\mathrm{B} 50-22, \mathrm{~A} 01-4, \mathrm{~A} 00 \\
-21, \mathrm{~B} 05-1, \mathrm{~B} 01-3, \\
\mathrm{~A} 09-1, \mathrm{~A} 80-3, \mathrm{~B} 86 \\
-2, \mathrm{~B} 50-5, \mathrm{~A} 00-0, \\
\mathrm{~B} 16-7, \mathrm{~B} 37-0 .\end{array}$ \\
\hline & $5-12$ (child) & Male & $\begin{array}{l}\mathrm{B} 50-15, \mathrm{~A} 01-4, \mathrm{~A} 00 \\
-21, \mathrm{~B} 05-1, \mathrm{~B} 01-2, \\
\mathrm{~A} 09-1, \mathrm{~A} 80-5, \mathrm{~B} 86 \\
-2, \mathrm{~B} 50-5, \mathrm{~A} 00-5, \\
\mathrm{~B} 16-7, \mathrm{~B} 37-1 .\end{array}$ \\
\hline & & Female & $\mathrm{B} 50-20, \mathrm{~A} 01-4, \mathrm{~A} 00$ \\
\hline
\end{tabular}




\begin{tabular}{|c|c|c|c|}
\hline Centre Code & Age & Sex & $\begin{array}{c}\text { Diagnosis (ICD-Code) } \\
\text { - Counts }\end{array}$ \\
\hline & \multirow[t]{3}{*}{$13-17$ (Teenager) } & Male & $\begin{array}{l}-21, \text { B } 05-1, \text { B } 01-2, \\
\text { A09-1, A } 80-3, \text { B } 86 \\
-2, \text { B50-5, A00-1, } \\
\text { B16-7, B37-1. }\end{array}$ \\
\hline & & & $\begin{array}{l}\text { B } 50-22, \text { A01-4, A00 } \\
-21, \text { B } 05-1, \text { B } 01-2, \\
\text { A09-1, A } 80-3, \text { B } 86\end{array}$ \\
\hline & & Female & $\begin{array}{l}-2, \mathrm{~B} 50-5, \mathrm{~A} 00-5, \\
\mathrm{~B} 16-7, \mathrm{~B} 37-1\end{array}$ \\
\hline & \multirow[t]{2}{*}{$18-59$ (Adult) } & Male & $\begin{array}{l}\text { B } 50-21, \text { A01-4, A00 } \\
-18, \text { B } 05-1, \text { B } 01-2, \\
\text { A09-1, A } 80-3, \text { B } 86 \\
-2, \text { B } 50-5, \text { A00-3, } \\
\text { B16-7, B37-0. }\end{array}$ \\
\hline & & Female & $\begin{array}{l}\text { B } 50-18, \text { A01-4, A00 } \\
-20, \text { B } 05-1, \text { B } 01-2, \\
\text { A09-1, A } 80-3, \text { B } 86 \\
-2, \text { B } 50-5, \text { A } 00-4, \\
\text { B16-7, B37-0. }\end{array}$ \\
\hline & \multirow[t]{3}{*}{$\begin{array}{l}60 \text { and above } \\
\text { (elder) }\end{array}$} & Male & $\begin{array}{l}\text { B } 50-15, \text { A } 01-4, \text { A00 } \\
-16, \text { B } 05-1, \text { B } 01-2, \\
\text { A09-1, A } 80-3, \text { B } 86 \\
-2, \text { B } 50-5, \text { A } 00-2, \\
\text { B16-7, B37-1. }\end{array}$ \\
\hline & & Female & $\begin{array}{l}\text { B } 50-20, \text { A } 01-4, \text { A } 00 \\
-15, \text { B } 05-1, \text { B } 01-2, \\
\text { A09-1, A } 80-3, \text { B } 86 \\
-2, \text { B } 50-5, \text { A } 00-4, \\
\text { B } 16-5, \text { B } 37-1 .\end{array}$ \\
\hline & & & $\begin{array}{l}\text { B } 50-20, \text { A } 01-4, \text { A } 00 \\
-14, \text { B } 05-1, \text { B } 01-2, \\
\text { A09-1, A } 80-3, \text { B } 86 \\
-1, \text { B } 50-5, \text { A } 00-2, \\
\text { B16-7, B } 37-0 .\end{array}$ \\
\hline
\end{tabular}

\subsection{The model for the user interface}

Figure 5 shows the model of the user interface for the proposed web-based grassroots epidemic alert system.

\subsection{Model for administrator interface}

Figure 6 shows the model of the administration interface for the proposed web-based grassroots epidemic alert system. 


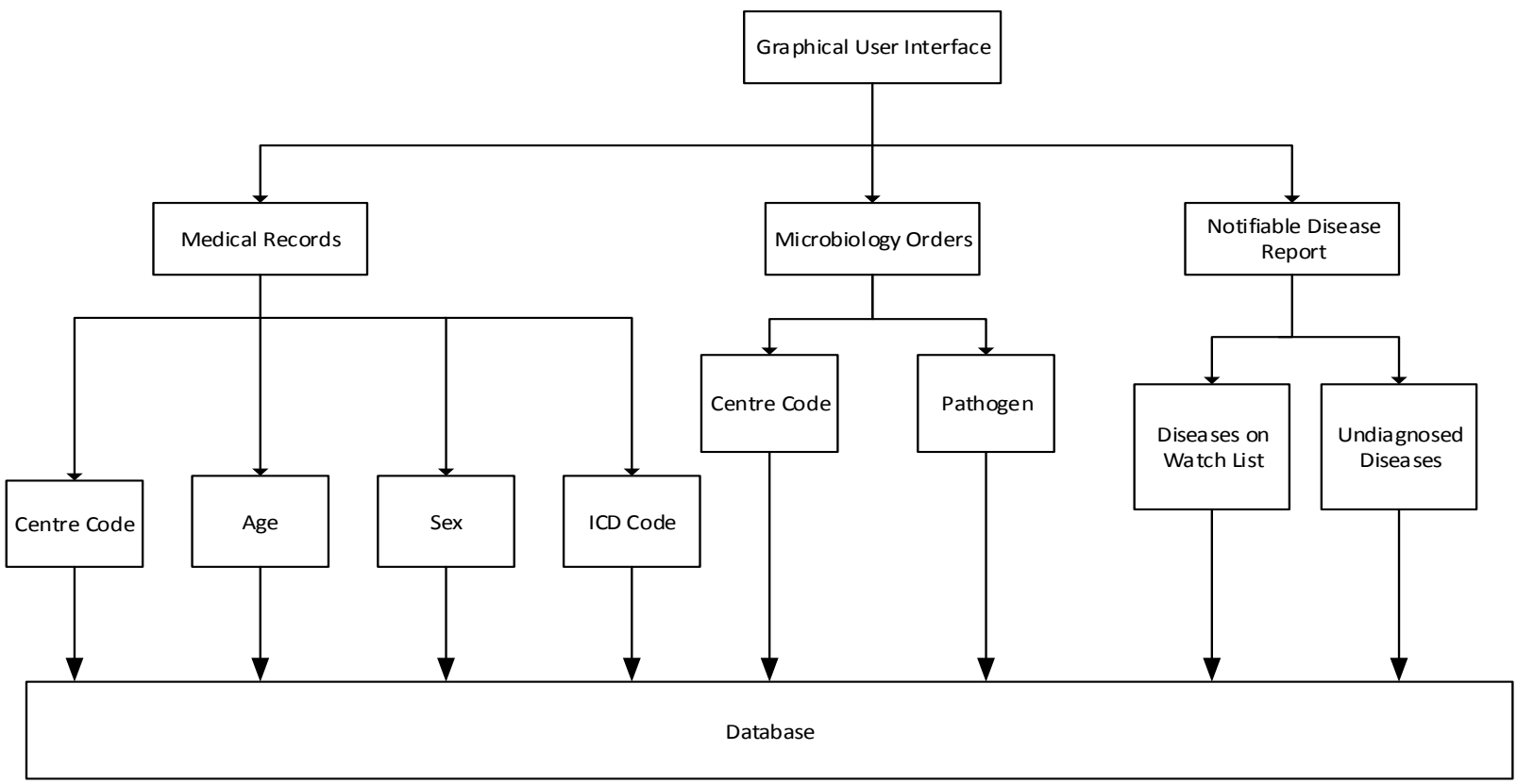

Figure 5. Model of the user interface for the proposed web-based grassroots epidemic alert system

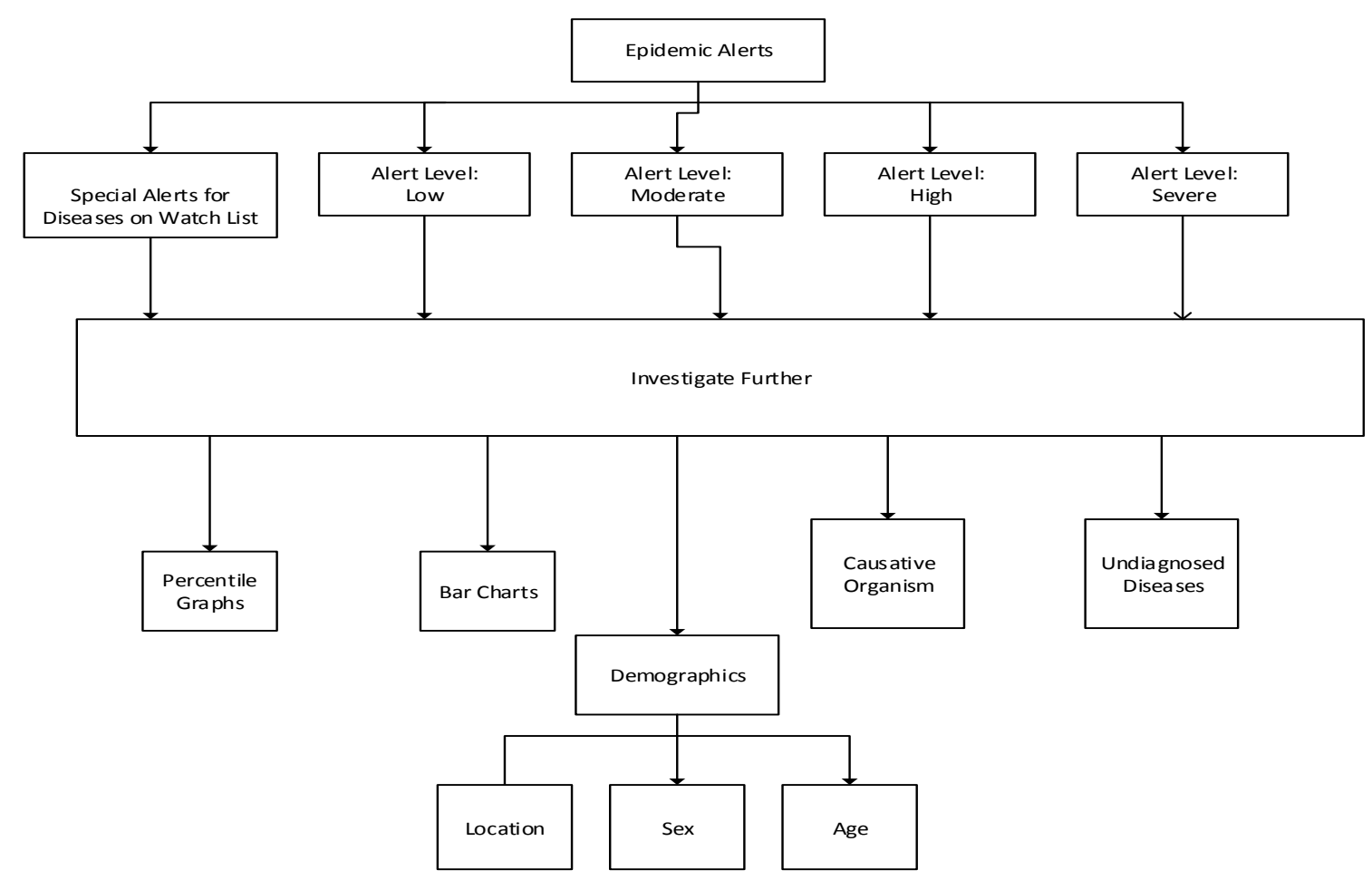

Figure 6. Model of the administration interface for the proposed web-based grassroots epidemic alert system

\section{RESULTS AND ANALYSIS}

The baseline values for all diseases being monitored is depicted in Figure 8 and Figure 9. It is based on the corresponding third quartile value for each ICD code. Some ICD codes like A20, A82, and A80 have corresponding baseline or threshold values of zero. This is because they are diseases on the special watch list. 
It is assumed that any recorded case of the diseases on the watch list should generate swift and appropriate action to protect public health.

In Figure 10, is shown the minimum, first quartile, median, third quartile and maximum values for ICD codes, A01, A36, B65, A33 and B58. It can be seen clearly from the plot that none of the diseases under observation has exceeded their respective threshold values. A close look at the plot reveals that the third quartile value for the observed diseases can be shown in a tabular format as shown in Table 5.

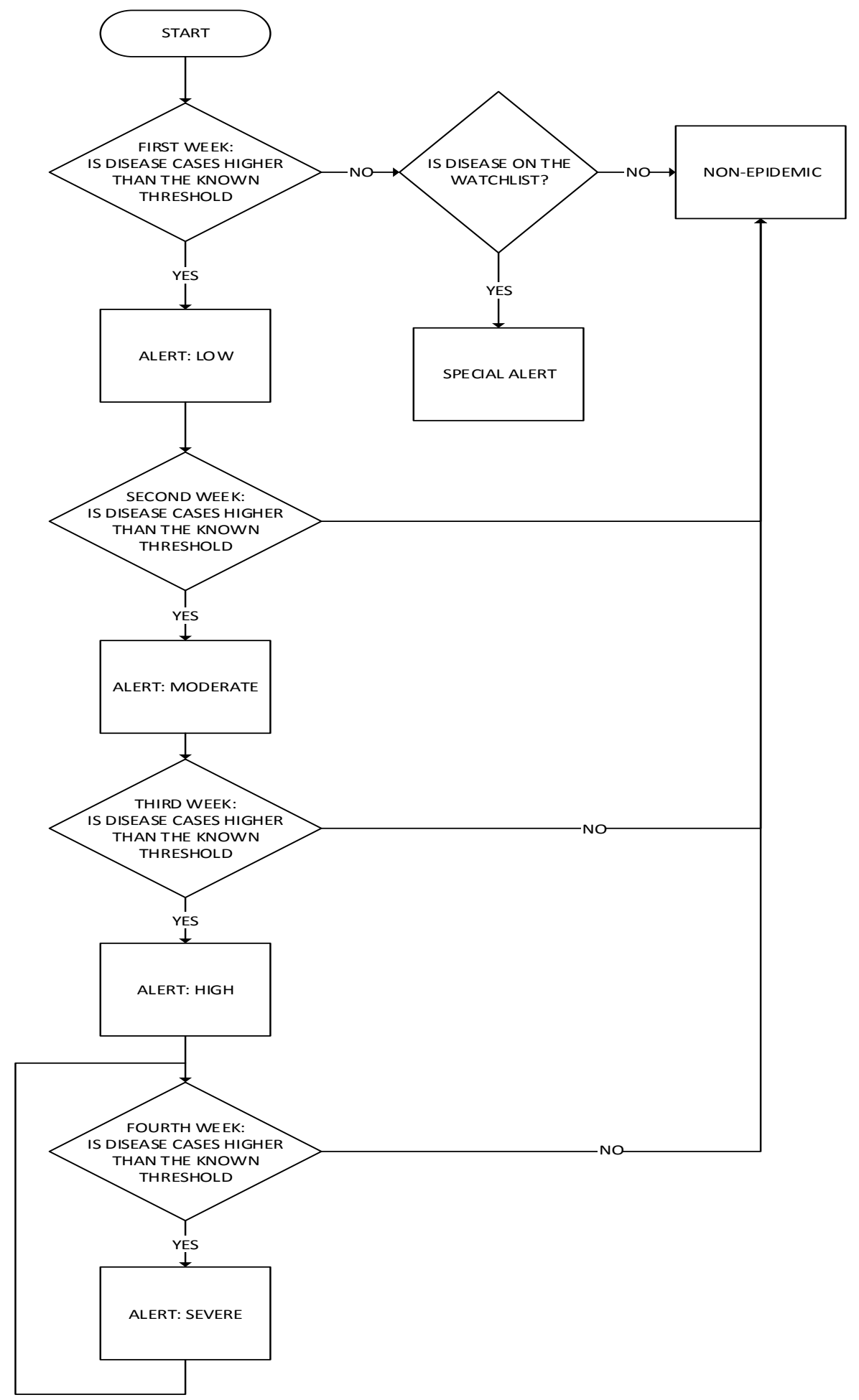

Figure 7. Algorithm for the proposed web-based grassroots epidemic alert system 


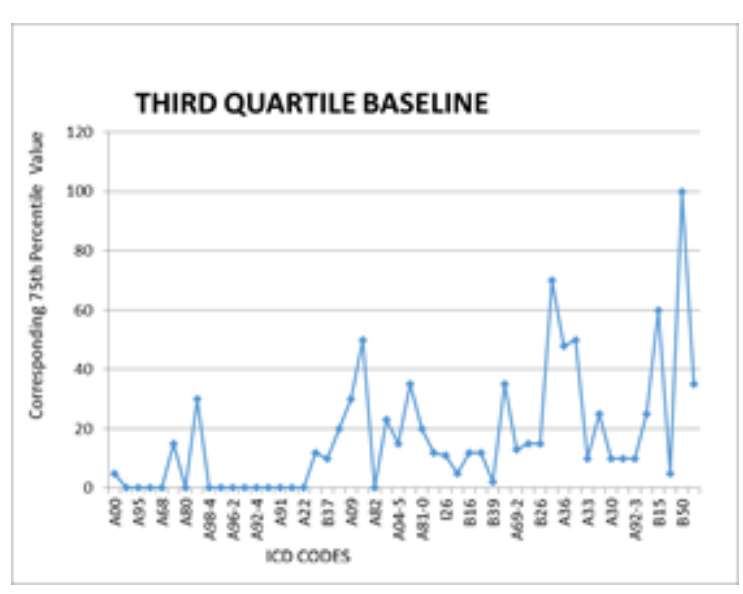

Figure 8. Baseline graph for each ICD code at the $75^{\text {th }}$ percentile (third quartile)

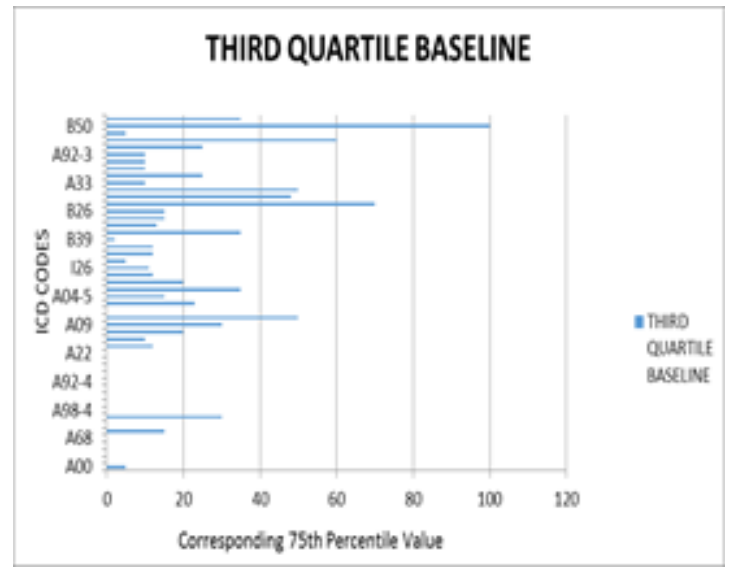

Figure 9. Bar representation of weekly thresholds for all fifty (50) diseases

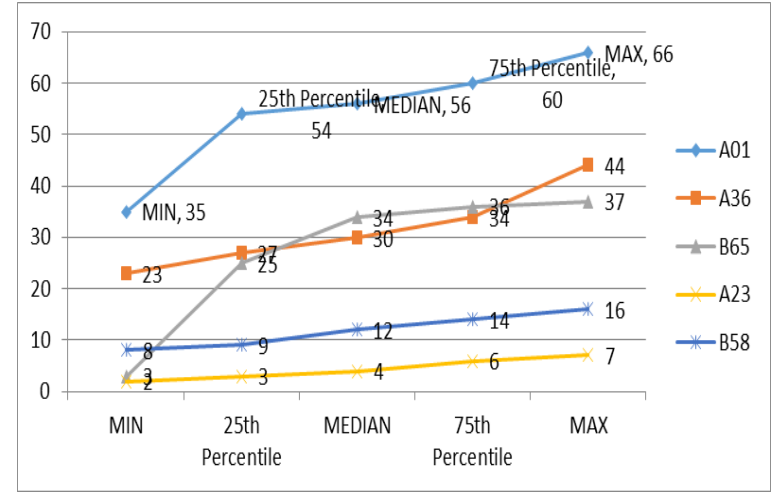

Figure 10. Weekly baseline graph for selected diseases

The actual third quartile values in Table 5 are all less than the baseline values. Therefore, the observed diseases are all non-epidemic.

Table 5. Comparison between Actual Third Quartile Values and Baseline Values

\begin{tabular}{cccc}
\hline $\begin{array}{c}\text { ICD } \\
\text { Code }\end{array}$ & $\begin{array}{c}\text { Actual Third } \\
\text { Quartile Value }\end{array}$ & Baseline Value & Epidemic Alerts \\
\hline A01 & 60 & 70 & Non-Epidemic \\
A36 & 34 & 48 & Non-Epidemic \\
A65 & 36 & 50 & Non-Epidemic \\
A23 & 6 & 10 & Non-Epidemic \\
B58 & 14 & 25 & Non-Epidemic \\
A01 & 60 & 70 & Non-Epidemic \\
A36 & 34 & 50 & Non-Epidemic \\
A65 & 36 & 10 & Non-Epidemic \\
A23 & 6 & 25 & Non-Epidemic \\
B58 & 14 & & Non-Epidemic \\
\hline
\end{tabular}

In Figure 11 there is an outlier. The outlier corresponds to the ICD code, B50. The outlier has a third quartile value that is greater than the threshold. But this is not to say that a disease has to be an outlier before the epidemic alarm is triggered. The only determining factor for triggering the epidemic alert system is the disease's third quartile value at the end of every week. From Table 6 it can be seen that Malaria (B50) has reached epidemic levels and a "Low Alert" was triggered 


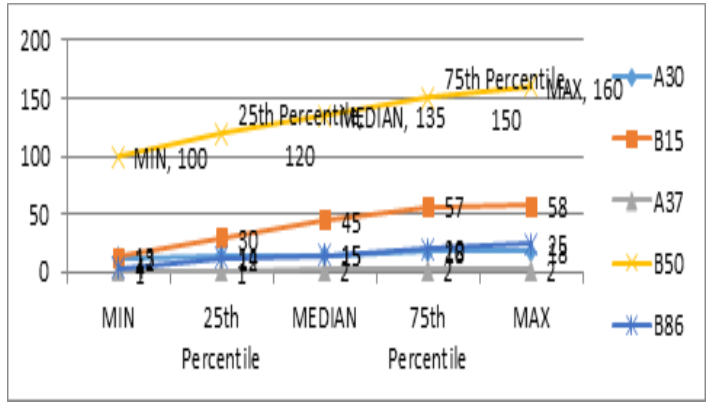

Figure 11. Weekly series graph with malaria (B50) at the "low alert" level

Table 6. Malaria (B50) at Epidemic Levels

\begin{tabular}{cccc}
\hline Disease & $\begin{array}{c}\text { Actual Third } \\
\text { Quartile Value }\end{array}$ & Baseline Value & Epidemic Alert \\
\hline K30 & 18 & 25 & Non-epidemic \\
B15 & 57 & 60 & Non-epidemic \\
A37 & 2 & 5 & Non-epidemic \\
B50 & 150 & 100 & Low Alert \\
B86 & 20 & 35 & Non-epidemic \\
\hline
\end{tabular}

From Figure 12, it can be observed that the third quartile values of A01 for three consecutive weeks were above the threshold (baseline) value of seventy (70). This triggered the "High Alert" for Typhoid and Paratyphoid Fevers. Table 7 shows this result clearly.

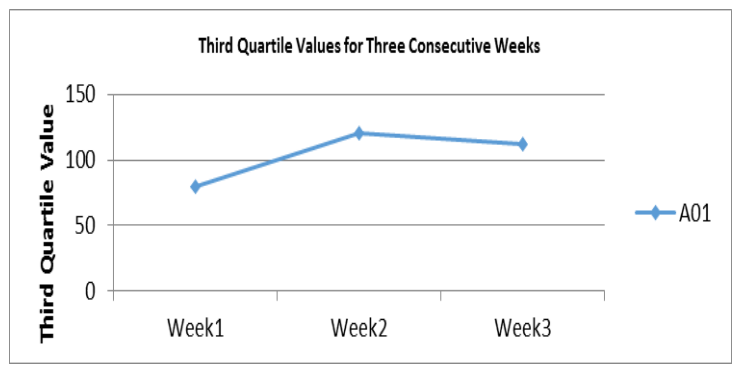

Figure 12. Series graph with typhoid (A01) at the "high alert" level

Table 7. Typhoid and Paratyphoid Fevers (A01) at High Alert

\begin{tabular}{cccc}
\hline Disease & Week 1 & Week 2 & Week 3 \\
\hline $\mathrm{A} 01$ & 80 & 120 & 112 \\
\hline
\end{tabular}

In Figure 13, the ICD code A00 has third quartile values that exceed the baseline for four consecutive weeks. Thus, the "Severe" alarm is triggered for ICD Code, A00. ICD code, A01, though having third quartile values that are above the threshold for three consecutive weeks, its epidemic status has been changed to non-epidemic because its third quartile value at the fourth week is less than the threshold value. This submission is clearly shown in Table 8.

A special exception is made for diseases that are on the watch list. In Figure 14, A80 has a third quartile value of zero (0) but a maximum value of one (1). Being on the watch list, A80 with a maximum value of one (1) triggered a "Special" alarm made for diseases on the watch list or diseases that have been confirmed eradicated officially. Table 9 sheds light on this special case.

A demographic analysis gives the percentage of infants, toddlers, children, teenagers, adults and aged persons affected by an epidemic outbreak [42]. It also provides information about the location of the outbreaks. It may also give an idea of the causative organism. A sample of the demographic analysis of Centre Code, H0186536085 for Cholera outbreak is shown in Figure 15. 


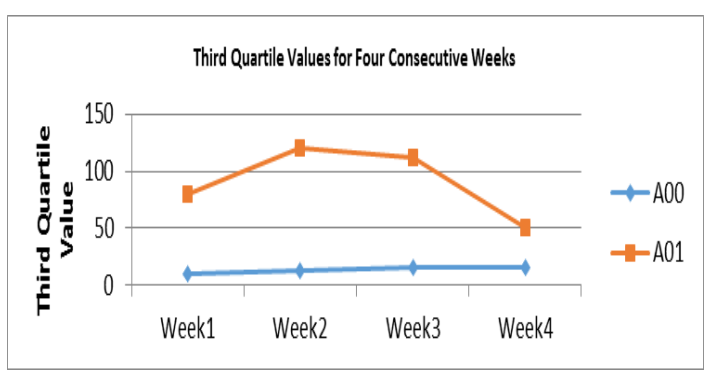

Figure 13. Series graph with cholera (A00) at the "severe alert" level

Table 8. Cholera (A00) and Typhoid Fever (A01) on "Severe" and Non-epidemic Alerts Respectively

\begin{tabular}{cccc}
\hline Disease & Week 1 & Week 2 & Week 3 \\
\hline A00 & 5 & 13 & 16 \\
A01 & 70 & 120 & 112 \\
\hline
\end{tabular}

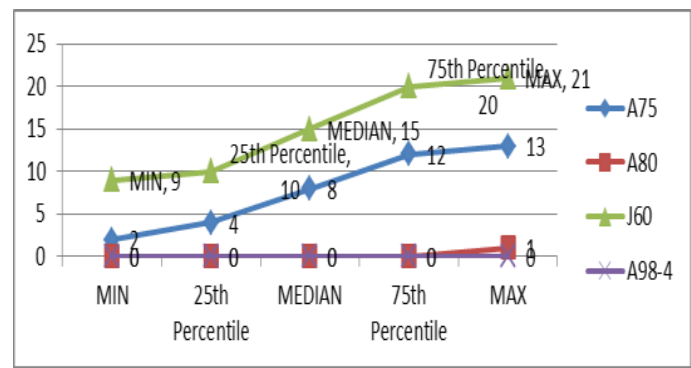

Figure 14. Weekly series graph with polio on "special alert"

Table 9. Polio (A80) on Special Alert

\begin{tabular}{cccc}
\hline \multirow{2}{*}{ Disease } & $\begin{array}{c}\text { Actual Third } \\
\text { Quartile Value }\end{array}$ & Baseline Value & Maximum Value \\
\hline A76 & 12 & 15 & 13 \\
A80 & 0 & 0 & 1 \\
J60 & 20 & 30 & 21 \\
A98 - 4 & 0 & 0 & 0 \\
\hline
\end{tabular}

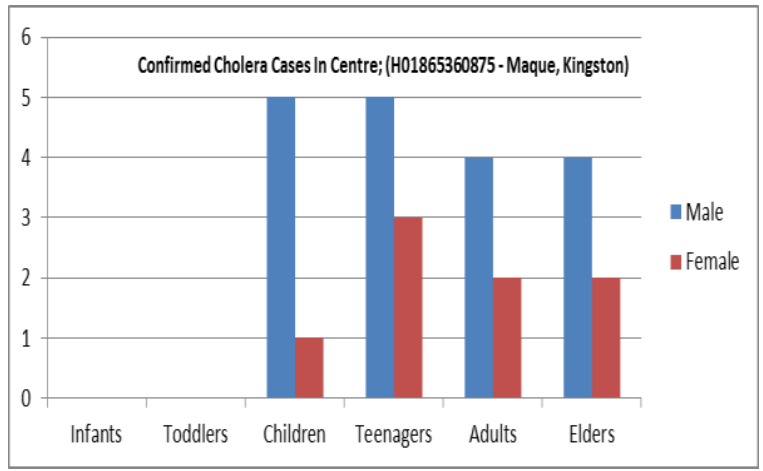

Figure 15. Sample demographic analysis

\section{CONCLUSION}

This proposed web-based epidemic alert system is a first-line step to standardizing web-based disease surveillance systems. It is a grassroots model that leverages on simplicity and "traditionality" as 
against complexity and "sophistication" to give timely epidemic alerts that can be disseminated to various stakeholders for appropriate action.

\section{FURTHER WORK}

A model for grading the severity of an epidemic and the corresponding response for each stage would be critically considered in the future. A more comprehensive and effective algorithm for epidemic detection would also be developed.

\section{ACKNOWLEDGEMENT}

This paper was partly sponsored by Covenant University, Ota, Ogun State, Nigeria.

\section{REFERENCES}

[1] J. Azeta, et al., “A Plan for Igniting Nigeria's Industrial Revolution”, International Journal of Scientific \& Engineering Research, vol. 7, p. 489, 2016.

[2] K. O. Okokpujie, et al., "An Intelligent Online Diagnostic System With Epidemic Alert", An Intelligent Online Diagnostic System With Epidemic Alert, vol. 2, 2017

[3] D. M. Morens, et al., "What is a Pandemic?," ed: The University of Chicago Press, 2009.

[4] E. Christaki, "New Technologies in Predicting, Preventing and Controlling Emerging Infectious Diseases", Virulence, vol. 6, pp. 558-565, 2015.

[5] N. Collier, "Uncovering Text Mining: A Survey of Current Work on Web-based Epidemic Intelligence", Global Public Health, vol. 7, p. 731Á749, 2012.

[6] J. L. Gardy and N. J. Loman, "Towards a Genomics-Informed, Real-Time, Global Pathogen Surveillance System", Nature Reviews Genetics, vol. 19, p. 9, 2018.

[7] O. Oluwagbemi, et al., "Ebinformatics: Ebola Fuzzy Informatics Systems on the Diagnosis, Prediction and Recommendation of Appropriate Treatments for Ebola Virus Disease (EVD)", Informatics in Medicine Unlocked, vol. 2, pp. 12-37, 2016.

[8] E. Adetiba, et al., "Experimental Investigation of Frequency Chaos Game Representation for in Silico and Accurate Classification of Viral Pathogens from Genomic Sequences", in International Conference on Bioinformatics and Biomedical Engineering, pp. 155-164, 2017.

[9] S. Yan, et al., "Utility and Potential of Rapid Epidemic Intelligence from Internet-based Sources", International Journal of Infectious Diseases, vol. 63, pp. 77-87, 2017.

[10] S. Pollett, et al., "Internet-based Biosurveillance Methods for Vector-Borne Diseases: Are they Novel Public Health Tools or just Novelties?," PLoS Neglected Tropical Diseases, vol. 11, p. e0005871, 2017.

[11] N. Schellpfeffer, et al., "Web-Based Surveillance of Illness in Childcare Centers", Health security, vol. 15, pp. 463-472, 2017.

[12] M. Dion, et al., "Big Data and the Global Public Health Intelligence Network (GPHIN)", Canada Communicable Disease Report, vol. 41, p. 209, 2015.

[13] S. H. Olson, et al., "Drivers of Emerging Infectious Disease Events as a Framework for Digital Detection," Emerging Infectious Diseases, vol. 21, p. 1285, 2015.

[14] J. Singh and V. Mansotra, "Salt Contamination Calculation in Insulators During Monsoon using Artificial Neural Network", Indonesian Journal of Electrical Engineering and Informatics (IJEEI), vol. 5, pp. 304-308, 2017.

[15] E. O. Nsoesie, et al., "New Digital Technologies for the Surveillance of Infectious Diseases at Mass Gathering Events," Clinical Microbiology and Infection, vol. 21, pp. 134-140, 2015.

[16] M. A. Al-garadi, et al., "Using Online Social Networks to Track a Pandemic: A Systematic Review", Journal of Biomedical Informatics, vol. 62, pp. 1-11, 2016.

[17] C. Rhee, et al., "Syndromic Surveillance System for Korea-US Joint Biosurveillance Portal: Design and Lessons Learned", Health security, vol. 14, pp. 152-160, 2016.

[18] K. Al-Surimi, et al., "The Potential of Social Media and Internet-based Data in Preventing and Fighting Infectious Diseases: From Internet to Twitter", in Emerging and Re-emerging Viral Infections, ed: Springer, pp. 131-139, 2016.

[19] V. S. Susan and T. Christopher, "Notice of Retraction Anonymising the Sparse Dataset: A New Privacy Preservation Approach while Predicting Diseases", Indonesian Journal of Electrical Engineering and Informatics (IJEEI), vol. 4, pp. 205-218, 2016.

[20] J. Choi, et al., "Web-based Infectious Disease Surveillance Systems and Public Health Perspectives: A Systematic Review", BMC Public Health, vol. 16, p. 1238, 2016.

[21] E. Samoff, et al., "Integration of Syndromic Surveillance Data into Public Health Practice at State and Local Levels in North Carolina", Public Health Reports, vol. 127, pp. 310-317, 2012.

[22] N. Mirza, et al., "Steps to a Sustainable Public Health Surveillance Enterprise A Commentary from the International Society for Disease Surveillance", Online Journal of Public Health Informatics, vol. 5, p. 210, 2013.

[23] M. O. Lwin, , et al., "Lessons From the Implementation of Mo-Buzz, a Mobile Pandemic Surveillance System for Dengue", JMIR Public Health and Surveillance, vol. 3, 2017. 
[24] L. Chimuanya and E. Ajiboye, "Socio-Semiotics of Humour in Ebola Awareness Discourse on Facebook", in Analyzing Language and Humor in Online Communication, ed: IGI Global, 2016, pp. 252-273.

[25] C. Abat, et al., "Traditional and Syndromic Surveillance of Infectious Diseases and Pathogens", International Journal of Infectious Diseases, vol. 48, pp. 22-28, 2016.

[26] F. Ayeni, et al., "Using Big Data Technology to Contain Current and Future Occurrence of Ebola Viral Disease and other Epidemic Diseases in West Africa", in International Conference in Swarm Intelligence, pp. 107-114, 2015.

[27] G. Eysenbach, "Infodemiology and Infoveillance: Framework for an Emerging Set Of Public Health Informatics Methods to Analyze Search, Communication and Publication Behavior on the Internet", Journal of Medical Internet Research, vol. 11, 2009.

[28] M. H. Mamoon, et al., "Visualization for Information Retrieval based on Fast Search Technology", Indonesian Journal of Electrical Engineering and Informatics (IJEEI), vol. 1, pp. 27-42, 2013.

[29] S. E. Davies and J. R. Youde, "Surveillance, Response, and Responsibilities in the 2005 International Health Regulations", The Politics of Surveillance and Response to Disease Outbreaks: The New Frontier for States and Non-state Actors, p. 9, 2015.

[30] D. Conesa, et al., "Bayesian Hierarchical Poisson Models with a hidden Markov Structure for the Detection of Influenza Epidemic Outbreaks", Statistical Methods in Medical Research, vol. 24, pp. 206-223, 2015.

[31] T. Vega, et al., "Influenza Surveillance in Europe: Comparing Intensity Levels Calculated using the Moving Epidemic Method", Influenza and Other Respiratory Viruses, vol. 9, pp. 234-246, 2015.

[32] A. A. Al-Qahtani, et al., "Zika Virus: A new Pandemic Threat", The Journal of Infection in Developing Countries, vol. 10, pp. 201-207, 2016.

[33] R. A. Ashton, et al., "The Usefulness of School-based Syndromic Surveillance for Detecting Malaria Epidemics: Experiences from a Pilot Project in Ethiopia”, BMC Public Health, vol. 16, p. $20,2015$.

[34] P. Hitchcock, et al., "Challenges to Global Surveillance and Response to Infectious Disease Outbreaks of International Importance", Biosecurity and Bioterrorism: Biodefense Strategy, Practice, and Science, vol. 5, pp. 206-227, 2007.

[35] S. Liu, et al., "epiDMS: Data Management and Analytics for Decision-Making from Epidemic Spread Simulation Ensembles", The Journal of Infectious Diseases, vol. 214, pp. S427-S432, 2016.

[36] R. F. Olanrewaju and A. W. Azman, "Intelligent Cooperative Adaptive Weight Ranking Policy via dynamic aging based on NB and J48 classifiers", Indonesian Journal of Electrical Engineering and Informatics (IJEEI), vol. 5, pp. 357-365, 2017.

[37] P. A. Idowu, et al., Web-Based Surveillance System for Periodontal Disease for Nigeria.

[38] K. E. L. Raul Isea, "Proposal for an Early Warning System Against an AH1N1 Influenza Pandemic in America", Mac Octagon Journals, vol. Vol 1, pp. pp. 65-71, 2017.

[39] G. Texier, et al., "Outbreak Definition by Change Point Analysis: A Tool for Public Health Decision?", BMC Medical Informatics and Decision Making, vol. 16, p. 33, 2016.

[40] Z. Harchaoui, et al., "Kernel Change-Point Analysis", in Advances in Neural Information Processing Systems, pp. 609-616, 2015.

[41] H. D. Teklehaimanot, et al., "Alert Threshold Algorithms and Malaria Epidemic Detection”, Emerging Infectious Diseases, vol. 10, p. 1220, 2004.

[42] S. N. Chinedu, et al., "Association Between Age, Gender and Body Weight in Educational Institutions in Ota, Southwest Nigeria”, Asian Journal of epidemiology, vol. 10, pp. 144-149, 2017. 